Article

\title{
Dietary Patterns of Adolescents from the Chilean Growth and Obesity Cohort Study Indicate Poor Dietary Quality
}

\author{
Angela Martínez Arroyo ${ }^{1,2}$, Camila Corvalán Aguilar ${ }^{3}$, Ximena Palma Molina ${ }^{1}$, \\ Ximena Ceballos Sanchez ${ }^{1}$ and Regina Mara Fisberg ${ }^{2, *(D)}$ \\ 1 School of Nutrition and Dietetics, Faculty of Pharmacy, University of Valparaíso, Valparaíso 2360102, Chile; \\ angela.martinez@uv.cl (A.M.A.); ximena.palma@uv.cl (X.P.M.); ximena.ceballos@uv.cl (X.C.S.) \\ 2 Department of Nutrition, School of Public Health, University of São Paulo, São Paulo 01246-904, Brazil \\ 3 Institute of Nutrition and Food Technology (INTA), University of Chile, Santiago 7830420, Chile; \\ ccorval@gmail.com \\ * Correspondence: regina.fisberg@gmail.com; Tel.: +55-(11)-3061-7869
}

Received: 3 June 2020; Accepted: 12 July 2020; Published: 14 July 2020

\begin{abstract}
Diet during adolescence can have lasting effects on nutritional status, health, and development. We hypothesized that dietary patterns with low-quality nutrition are associated with overweightness. We collected data for 882 Chilean adolescents from the Growth and Obesity Cohort Study (mean age: 12 years). Dietary intake was assessed through 24-h recalls and weight status data were obtained during clinical visits. Dietary patterns were obtained through exploratory factor analysis. Multiple logistic regression models were used to examine cross-sectional associations between dietary patterns and overweight (BMI z-score $\geq 1 \mathrm{SD}$ ). Four dietary patterns were identified: "Breakfast/Light dinner", "Natural foods", “Western”, and "Snacking”. "Breakfast/Light dinner", "Western", and "Snacking" patterns provided higher energy and excess nutrients (sodium, saturated fat, and added sugar). Moreover, adolescents with higher adherence to "Western" or "Snacking" patterns (third tertile) had higher odds of being classified as overweight (OR = 1.67; 95\% CI: $1.103-2.522$ and OR $=1.86 ; 95 \% \mathrm{CI}: 1.235-2.792$, respectively) than those with lower adherence (first tertile). "Natural foods" pattern was also associated with overweightness (OR = 1.83; 95\% CI: 1.219-2.754). These dietary patterns were associated with overconsumption of nutrients of public health concern. Three of the four main dietary patterns were associated with overweightness. These results highlight the need of prioritizing adolescents on obesity prevention strategies.
\end{abstract}

Keywords: dietary pattern; adolescent diet; dietary quality; exploratory factor analysis

\section{Introduction}

Adolescence is a critical stage in life, characterized by an accelerated growth rate and multiple physical and social changes that prepare a person for adulthood [1]. Diet quality during this period is important as it can affect adolescents' nutritional status and can have long-lasting effects on their future feeding behavior, nutritional status, early life health, and the development of their offspring [2-4]. Evidence relating to diet during this period has been found in high-income countries (HIC) [1,2]. Nonetheless, in the regions of Latin America and the Caribbean (LAC), dietary aspects are not well studied. Thus, information on adolescents feeding habits are usually extrapolated from adult data findings, highlighting the need for further evidence [5].

The rising trend of overweightness and obesity in children and adolescents has plateaued in many HIC and industrialized low to middle-income countries (LMIC), albeit at high levels [6]. In the last few decades, in LAC, there has been a shift towards diets based mostly on foods with added sugar and salt, 
refined carbohydrates, grain-based desserts, and savory snacks [7]. In combination with a decline in physical activity, these diets have led to a rapid increase in childhood obesity in LAC countries $[5,7,8]$.

Among LAC countries, Chile has one of the highest prevalence rates (up to 31\%) of overweight and obesity in children and adolescents $[5,8]$. In addition, Chile has the highest measured per capita sales of sugar-sweetened beverages (SSBs), junk food, salted snacks, and foods that are high in added sugar, saturated fats, and sodium [7] among LAC countries.

There is now evidence that dietary patterns, rather than individual nutrients or foods, contribute to disease trajectories because empirical dietary patterns evaluate the food consumption under a multidimensional approach that takes into account the effects of the overall diet [9-14]. However, how the consumption of different foods is integrated within specific dietary patterns, particularly in LAC countries where there is great cultural and dietary diversity, is unclear [15]. Therefore, the objective of the current study is to characterize the dietary patterns of a cohort of low-middle income Chilean adolescents and to assess the associations of these diets with socio-demographic factors and excess body weight. Given that Chile is an LAC country with one of the highest obesity rates, we hypothesize that most common dietary patterns will be of low-quality nutrition (high in saturated fat, added sugars, and sodium) and will be associated with overweightness. Moreover, data were collected before the implementation of a set of regulatory actions to prevent obesity (warning labels, marketing, and control of food sold in schools) [16], and therefore, can serve as a baseline for assessing the effectiveness of the regulations among a critical age-group such as adolescents.

\section{Materials and Methods}

\subsection{Study Population}

Our study sample was obtained from adolescents participating in the Growth and Obesity Chilean Cohort Study (GOCS). Briefly, GOCS is a population-based ambispective cohort of 1195 children, born in 2002-2003, from six low-middle income counties from the southeast area of Santiago, Chile. Participants were children who were born at term (37-42 weeks), had a birth weight of between 2500 and $4500 \mathrm{~g}$, and were free from conditions that could affect their growth, such as food allergies and genetic and metabolic diseases. Details of the design, objectives, and recruitment strategies of the GOCS have been described elsewhere $[17,18]$. GOCS contains data on anthropometric measurements and sexual maturation evaluations collected every six months since 2006 [19]. Dietary assessments were carried out in person during clinic visits in 2013 with the use of 24-h recalls (24HR).

The present study used data collected during the 8-9-year follow-up. In the present study (Figure 1), all adolescents were evaluated in 2014-2015, with at least one 24HR per participant $(n=913)$, and anthropometric measurements were obtained during the same clinic visit $(n=882)$. We excluded 31 adolescents ( 21 boys and 11 girls) because no anthropometric measurements were available. The final sample of this study included 882 adolescents. There were no differences in age and energy intakes between the total sample and the excluded participants (i.e., mean ages 12.07 vs. 12.02 years and energy intake 1828 vs. 1827 mean kilocalories/day, respectively).

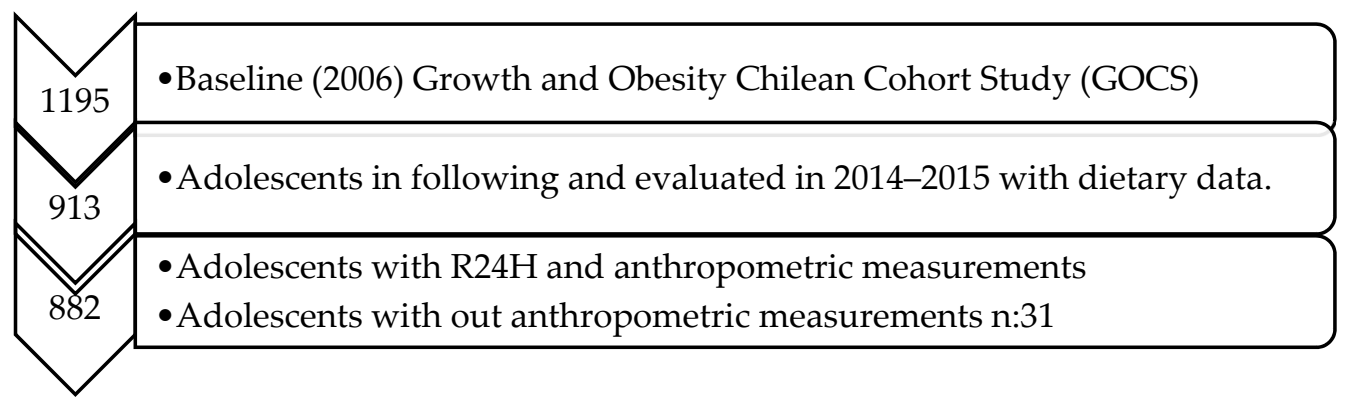

Figure 1. Flowchart for participant selection in the study. 
The informed consent and the study protocol were approved by the Institutional Reviewer Board from the Institute of Nutrition and Food Technology, University of Chile. Before data collection, parents/caregivers provided written informed consent and adolescents provided written assent.

\subsection{Dietary Data Collection}

Dietary data were obtained through two non-consecutive 24HR interviews on different weekdays, weekends, and seasons, following the "Multiple Pass Method" [20]. About $60 \%$ of the second recalls were collected 6 months after the first recall. The interviews were conducted in person by trained dieticians in the presence of the person responsible for preparing and serving meals to the adolescents to avoid food misreporting. Dietary intake data included the time of the meal and between meals, names of dishes and cooking methods, and a list of food, beverages, and serving sizes (household measures), and was obtained with the aid of a photo atlas from the National Survey of Food Consumption of Chile [21]. Energy and nutrient intakes from 24HRs were calculated using the Nutrition Data System for Research (NDSR) program (version of 20014, NCC, University of Minnesota, Minneapolis, MN, USA), which uses the United States Department of Agriculture (USDA) database as the main food composition table. Therefore, all foods and beverages listed in the $24 \mathrm{HR}$ interviews were matched with those in the NDSR database through their general description (i.e., name, preparation, and cooking method). Energy and macronutrient values available in the Chilean Food Composition table [22], local food industry composition tables, and/or nutrition food labels were compared to values described by the software. A concordance rate between $80 \%$ and $120 \%$ for each parameter analyzed was required to accept food harmonization. Chilean preparations, such as charquicán, cazuela, and sopaipillas, were added as recipes to the NDSR because they are commonly consumed by Chilean adolescents and were not in the software database. We observed 24HRs with values over $3500 \mathrm{kcal}$ and under $500 \mathrm{kcal}$ [23], which were revised to rule out digitalization errors. We did not exclude any participant with these values.

In total, 1053 different foods were reported in two $24 \mathrm{HRs}$, but 993 were consumed by at least $5 \%$ of the sample. These food items were collapsed into 29 food categories on the basis of their nutritional value, the coefficient correlation between groups, commonality values, food preparation methods, and Chilean dietary behaviors (Supplemental files Table S1).

\subsection{Anthropometric Measurements}

Anthropometric measurements were obtained using validated techniques, and they were duplicated by two trained dietitians using standard procedures (one for each sex, intra-, and inter-class correlation > 0.9) [19]. Bodyweight was measured with a standardized scale (TANITA BC-418) with $0.1 \mathrm{~kg}$ precision, and height was measured using a longitudinal stadiometer (SECA 222) ranging from 6 to $230 \mathrm{~cm}$ in capacity and a precision of $0.1 \mathrm{~cm}$. Body mass index (BMI) was defined using the standard formula: weight $(\mathrm{kg})$ divided by height squared $\left(\mathrm{m}^{2}\right)$. The BMI $\mathrm{z}$-score was calculated according to the World Health Organization (WHO) definition for age and sex, and it was used to classify the adolescents' body weight status as underweight $(\leq-1 \mathrm{SD})$, normal weight $(<-1 \mathrm{SD}$ and $<+1 \mathrm{SD}$ ), overweight ( $\geq+1 \mathrm{SD}$ and $<+2 \mathrm{SD})$, and obese $(\geq+2 \mathrm{SD})$ [24]. We used the term overweight (outcome variable) when referring to overweight and obesity nutritional status combined.

\subsection{Covariates}

\subsubsection{Sexual Maturation}

A pediatric endocrinologist evaluated the adolescents' breast and genital development and classified them according to the Tanner stages. Girls were evaluated according to their breast development through inspection and palpation using the Tanner scale. Boys were evaluated according to their genitalia development through palpation using the Prader orchidometer [25]. 


\subsubsection{Maternal Self-Reported Information}

The following information was obtained: (i) maternal highest education level ( $\geq 12$ y or $<12$ y), (ii) children's school administrative status (private or public), (iii) hours of sleep (meeting or not meeting the recommendations $\geq 9 \mathrm{~h} /$ day or $<9 \mathrm{~h} /$ day), and (iv) participation in the school feeding program (yes or no).

The school feeding program aims to provide daily food services (breakfast, lunch, light dinner (a typical Chilean meal served sometime between 5:00 and 8:00 pm, comparable to teatime), snacks, and dinner, as appropriate) to all students from vulnerable sections of society in Chile's public schools. In the present study, $30 \%$ of the adolescents were reported to be beneficiaries of the school feeding program.

\subsubsection{Maternal Weight Status}

A trained dietitian measured the participants' mothers' weights and heights to calculate their BMI and classify their weight status according to the WHO guidelines [26].

\subsection{Statistical Analysis}

Firstly, we used statistical modeling techniques incorporated into the Multiple Source Method online platform, which were used to estimate the usual intake of each food group in grams [27]. Exploratory factor analysis (EFA) was used to identify the dietary patterns from 29 food groups. Initially, factors with eigenvalues greater than or equal to 1.5 were retained. In the second stage, the scree plot was visually inspected, and it suggested the retention of four factors. The Varimax orthogonal rotation was applied for better interpretation of the factor loading matrix and to ensure the independence of the factors derived. Factor loadings greater than or equal to $|0.25|$ were considered to contribute to the pattern [28]. The retained patterns were named according to their interpretability, the characteristics of the food in each dietary pattern, and the commonalities observed, which reflect the level of linkage between the variable (food group) and the extracted factor. Other food grouping systems were tried but they did not allow us to create dietary patterns because of the low factor loading and their interpretability. For each participant, the factor score of each dietary pattern was calculated using the regression scoring method [29]. The dietary pattern scores were then stratified into tertiles and used as independent variables. The $\chi^{2}$ Pearson's test was used to investigate the associations between the tertile adherence to dietary patterns and weight status, Tanner stages, and socio-demographic and maternal variables (bivariate analyses).

We also used the Multiple Source Method to estimate the usual intake of energy and critical nutrients of public health concern (i.e., sodium, added sugars, and saturated fats) [30]. Individual usual nutrient intakes were expressed in grams or micrograms per $1000 \mathrm{kcal}$ of energy, or as total percentage of energy intake.

Medians and interquartile ranges were provided according to factor score tertiles. The associations between usual nutrient intakes and adherence to dietary patterns were calculated by applying the Kruskal-Wallis and Dunn tests.

Misreporting of energy intake was estimated with the following equation: EI (energy intake) - EER (estimated energy requirements)/EER $\times 100$ [31]. Misreporting was differentially associated to the dietary patterns (i.e., breakfast/light dinner $r=0.02$, natural foods $r=0.02$, Western $r=0.14$, snacking $r=0.15$ ); therefore, this variable was adjusted for in all regression models. Logistic regression models were used to investigate the association between adherence (tertiles) to each dietary pattern and overweight (dummy variable defined herein as overweight [yes or no]) with covariates adjusted. All analyses were performed using STATA software version 15 (College Station, TX 77845) with significance values established for all tests at $p<0.05(5 \%)$. 


\section{Results}

\subsection{Demographics and Lifestyle Characteristics}

The sample from GOCS included 882 respondents (mean age 12 years, SD = \pm 0.7 ), of which $50.8 \%$ were female. The majority of the adolescents were classified as overweight or obese (51.6\%). Almost half of the participants (49.7\%) were classified into the fourth and fifth Tanner stages of sexual maturation. More than $60 \%$ of the participants slept for more than $9 \mathrm{~h} /$ day and studied at private schools and one third were beneficiaries of the school feeding program. In relation to the maternal socio-demographic and weight status, over half $(65.5 \%)$ of the participant mothers did not have more than 12 years of study, and $38.3 \%$ were classified as obese (Table 1 ).

Table 1. Anthropometric, sociodemographic, and maternal characteristics of 882 Chilean adolescents, GOCS Study 2014-2015.

\begin{tabular}{|c|c|c|}
\hline Characteristics & $n$ & $\%$ \\
\hline \multicolumn{3}{|l|}{ Sex } \\
\hline Male & 434 & 49.2 \\
\hline Female & 448 & 50.8 \\
\hline \multicolumn{3}{|l|}{ Tanner Stage ${ }^{¥}$} \\
\hline 1 & 54 & 6.1 \\
\hline 2 & 222 & 25.2 \\
\hline 3 & 144 & 16.3 \\
\hline 4 & 257 & 29.1 \\
\hline 5 & 182 & 20.6 \\
\hline Missing & 23 & 2.6 \\
\hline \multicolumn{3}{|c|}{ Weight status (BMI-for-age $z$ score) * } \\
\hline Underweight & 43 & 4.9 \\
\hline Normal Weight & 383 & 43.5 \\
\hline Overweight & 275 & 31.2 \\
\hline Obesity & 180 & 20.4 \\
\hline \multicolumn{3}{|l|}{ Sleep (hours) } \\
\hline$\geq 9 \mathrm{~h}$ & 236 & 26.8 \\
\hline$<9 \mathrm{~h}$ & 532 & 60.3 \\
\hline Missing & 114 & 12.9 \\
\hline \multicolumn{3}{|c|}{ School administrative status } \\
\hline Private & 543 & 61.6 \\
\hline Public & 330 & 37.4 \\
\hline Missing & 9 & 1 \\
\hline \multicolumn{3}{|c|}{ School feeding program } \\
\hline No & 603 & 68.4 \\
\hline Yes & 279 & 31.6 \\
\hline \multicolumn{3}{|l|}{ Maternal Obesity $^{\dagger}$} \\
\hline No & 520 & 59.0 \\
\hline Yes & 338 & 38.3 \\
\hline Missing & 24 & 2.7 \\
\hline \multicolumn{3}{|c|}{ Maternal education (years) } \\
\hline$<12$ years & 578 & 65.5 \\
\hline$\geq 12$ years & 280 & 31.8 \\
\hline Missing & 24 & 2.7 \\
\hline
\end{tabular}

* BMI-for-age $z$ score: underweight $\leq-1 \mathrm{SD}$, normal $<-1 \mathrm{SD}$ and $<+1 \mathrm{SD}$, overweight $\geq+1 \mathrm{SD}$ and $<+2 \mathrm{SD}$, obesity $\geq+2$ SD [24]; † Maternal obesity $=\mathrm{BMI} \geq 30 \mathrm{~kg} / \mathrm{m}^{2}$. $¥$ Tanner status: girls were evaluated according to their breast development and boys were evaluated according their genitalia development [25]. 


\subsection{Identification of Dietary Patterns}

Exploratory factor analysis allowed the identification of four dietary patterns: (i) "Breakfast/Light Dinner", consisting of tea, sugar, bread, margarine/butter, and cold cuts (positive loadings); (ii) "Natural foods", consisting of meats, vegetables, and salad dressing (positive loadings); (iii) "Western", consisting of processed meats, soft drinks, rice, pastas, potatoes, mayonnaise, ketchup (positive loadings) and milk, homemade dishes (typical Chilean recipes, such as charquicán, carbonada, pastel de choclo, cazuela), and chocolate powder (negative loadings); and (iv) "Snacking", consisting of flavored milk, cookies, and cakes (positive loadings), and yoghurts and ready-to-eat cereals (negative loadings). These patterns resulted in a total intake variance of $7.4 \%, 6.4 \%, 5.6 \%$, and $5.4 \%$, respectively (Table 2).

Table 2. Dietary Patterns practiced by GOCS adolescents (n:882), Chile 2014-2015.

\begin{tabular}{|c|c|c|c|c|}
\hline Food and Beverage Groups & Breakfast/Light Dinner & Natural Foods & Western & Snacking \\
\hline Milk & -0.22 & 0.00 & -0.32 & -0.12 \\
\hline Flavored milk & -0.24 & -0.20 & 0.06 & $0.28 *$ \\
\hline Yogurt & -0.10 & 0.03 & 0.01 & $-0.73^{*}$ \\
\hline Cheeses & 0.06 & -0.06 & 0.16 & 0.11 \\
\hline Meats & -0.16 & $0.50 *$ & $0.29 *$ & 0.07 \\
\hline Cold cuts & $0.27 *$ & -0.15 & $0.27^{*}$ & 0.00 \\
\hline Processed meats & 0.01 & -0.20 & $0.41 *$ & -0.07 \\
\hline Junk Food & -0.18 & -0.23 & 0.11 & 0.09 \\
\hline Flavored juices & -0.22 & 0.16 & -0.07 & 0.24 \\
\hline Soft drink & -0.07 & 0.03 & $0.41 *$ & 0.14 \\
\hline Tea and coffee & $0.73 *$ & 0.04 & -0.11 & 0.08 \\
\hline Bread & $0.64 *$ & -0.04 & 0.18 & 0.11 \\
\hline Ready to eat cereal & -0.09 & 0.03 & -0.02 & $-0.77^{*}$ \\
\hline Rice, pastas, potatoes & 0.02 & 0.16 & $0.47^{*}$ & -0.05 \\
\hline Vegetables & 0.09 & $0.81 *$ & -0.01 & 0.00 \\
\hline Fresh fruit & 0.08 & 0.16 & -0.23 & 0.05 \\
\hline Eggs & 0.02 & 0.04 & 0.00 & -0.07 \\
\hline Homemade dishes & 0.14 & -0.11 & $-0.62 *$ & 0.01 \\
\hline Soups & -0.10 & 0.18 & -0.19 & 0.13 \\
\hline Cracker and salt snack & -0.14 & -0.11 & 0.16 & 0.03 \\
\hline Confectionery and chocolate & -0.07 & 0.02 & -0.03 & 0.17 \\
\hline Cookies & -0.23 & -0.07 & -0.11 & $0.29 *$ \\
\hline Cakes & -0.09 & 0.03 & -0.19 & $0.25 *$ \\
\hline Desserts and ice cream & 0.05 & 0.08 & 0.01 & -0.03 \\
\hline Sugar & $0.70 *$ & 0.10 & -0.12 & 0.08 \\
\hline Chocolate powder & -0.19 & -0.03 & $-0.27 *$ & 0.01 \\
\hline Margarine and butter & $0.49 *$ & -0.08 & 0.05 & -0.09 \\
\hline Oil, lemon, salt, vinegar (for salad) & 0.00 & $0.79 *$ & 0.03 & -0.07 \\
\hline Mayonnaise and ketchup & -0.01 & 0.04 & $0.31 *$ & 0.06 \\
\hline$\%$ of explained variance & 7.42 & 6.42 & 5.64 & 5.43 \\
\hline $\begin{array}{l}\% \text { of accumulated explained } \\
\text { variance }\end{array}$ & 7.42 & 13.84 & 19.48 & 24.90 \\
\hline Eigenvalues & 2.16 & 1.88 & 1.63 & 1.55 \\
\hline
\end{tabular}

\subsection{Adherence to Dietary Patterns, Socio-Demographics, Weight Status, and Maternal Variables}

The frequency of adherence (\%) to dietary patterns and the bivariate relationships with socio-demographics and weight status, i.e., pubertal and maternal weight statuses, are shown in Table 3. Adherence to the "Breakfast/Light dinner" pattern was higher among underweight and obese adolescents $(p=0.01)$. Adherence to the "Natural foods" pattern was higher among adolescents who were not recipients of the school feeding program $(p=0.04)$. The adherence to the "Western" pattern was higher among male adolescents $(p=0.04)$ and those who did not participate in the school feeding program $(p=0.04)$. Adherence to the "Snacking" pattern was higher in adolescents that partook in the school feeding program $(p=0.01)$. 
Table 3. Adherence (\%) according to sociodemographic, anthropometric, and maternal nutrition status of 882 Chilean adolescents, GOCS Study 2014-2015 Chile.

\begin{tabular}{|c|c|c|c|c|c|c|c|c|c|c|c|c|c|c|c|}
\hline \multirow{2}{*}{\multicolumn{2}{|c|}{ Characteristics }} & \multicolumn{7}{|c|}{ Breakfast/Light Dinner } & \multicolumn{7}{|c|}{ Natural Foods } \\
\hline & & \multicolumn{2}{|c|}{ T1 } & \multicolumn{2}{|c|}{ T2 } & \multicolumn{2}{|c|}{ T3 } & \multirow[t]{2}{*}{$p$} & \multicolumn{2}{|c|}{ T1 } & \multicolumn{2}{|c|}{ T2 } & \multicolumn{2}{|c|}{ T3 } & \multirow[t]{2}{*}{$p$} \\
\hline & & $\%$ & $n$ & $\%$ & $n$ & $\%$ & $n$ & & $\%$ & $n$ & $\%$ & $n$ & $\%$ & $n$ & \\
\hline \multirow[t]{2}{*}{ Sex } & Male & 30.2 & 131 & 34.1 & 148 & 35.7 & 155 & 0.126 & 35.5 & 154 & 33.4 & 145 & 31.1 & 135 & 0.292 \\
\hline & Female & 36.4 & 163 & 32.6 & 146 & 31.0 & 139 & & 31.3 & 140 & 33.3 & 149 & 35.5 & 159 & \\
\hline \multirow[t]{2}{*}{ Tanner stage ${ }^{¥}$} & $1-3$ & 31.4 & 132 & 33.6 & 141 & 35.0 & 147 & 0.617 & 36.0 & 151 & 32.9 & 138 & 31.2 & 131 & 0.243 \\
\hline & $4-5$ & 34.4 & 151 & 33.0 & 145 & 32.6 & 143 & & 30.8 & 135 & 34.2 & 150 & 35.1 & 154 & \\
\hline \multirow[t]{4}{*}{ Weight status $\ddagger$} & Underweight & 30.2 & 13 & 23.3 & 10 & 46.5 & 20 & $0.013 *$ & 32.6 & 14 & 32.6 & 14 & 34.9 & 15 & 0.167 \\
\hline & Normal Weight & 36.2 & 139 & 30.0 & 115 & 33.9 & 130 & & 37.0 & 142 & 34.6 & 133 & 28.4 & 109 & \\
\hline & Overweight & 33.1 & 91 & 40.0 & 110 & 26.9 & 74 & & 31.3 & 86 & 33.1 & 91 & 35.6 & 98 & \\
\hline & Obesity & 28.3 & 51 & 32.8 & 59 & 38.9 & 70 & & 28.9 & 52 & 31.1 & 56 & 40.0 & 72 & \\
\hline \multirow[t]{2}{*}{ Sleep Hours } & $\geq 9 \mathrm{~h}$ & 33.5 & 79 & 34.8 & 82 & 31.8 & 75 & 0.727 & 32.2 & 76 & 37.3 & 88 & 30.5 & 72 & 0.324 \\
\hline & $<9 h$ & 35.7 & 190 & 32.0 & 170 & 32.3 & 172 & & 34.6 & 184 & 31.8 & 169 & 33.7 & 179 & \\
\hline \multirow{2}{*}{$\begin{array}{c}\text { School } \\
\text { administrative } \\
\text { status }\end{array}$} & Public & 30.6 & 101 & 32.4 & 107 & 37.0 & 122 & 0.186 & 34.9 & 115 & 32.7 & 108 & 32.4 & 107 & 0.728 \\
\hline & Private & 34.8 & 189 & 34.1 & 185 & 31.1 & 169 & & 32.2 & 175 & 34.1 & 185 & 33.7 & 183 & \\
\hline \multirow{2}{*}{$\begin{array}{c}\text { School feeding } \\
\text { program }\end{array}$} & Yes & 32.6 & 91 & 33.3 & 93 & 34.1 & 95 & 0.939 & 37.3 & 104 & 35.1 & 98 & 27.6 & 77 & 0.042 * \\
\hline & No & 33.7 & 203 & 33.3 & 201 & 33.0 & 199 & & 31.5 & 190 & 32.5 & 196 & 36.0 & 217 & \\
\hline \multirow{2}{*}{$\begin{array}{l}\text { Maternal } \\
\text { Obesity }\end{array}$} & Yes & 36.5 & 100 & 32.7 & 113 & 30.8 & 125 & 0.069 & 33.3 & 113 & 33.1 & 114 & 33.7 & 111 & 0.966 \\
\hline & No & 29.6 & 190 & 33.4 & 170 & 37.0 & 160 & & 33.4 & 173 & 33.7 & 172 & 32.8 & 175 & \\
\hline \multirow{2}{*}{$\begin{array}{c}\text { Maternal } \\
\text { education } \\
\text { years }\end{array}$} & $\geq 12$ years & 35.3 & 204 & 32.7 & 189 & 32.0 & 185 & 0.304 & 31.8 & 184 & 32.9 & 190 & 35.3 & 204 & 0.076 \\
\hline & $<12$ years & 30.0 & 84 & 35.7 & 100 & 34.3 & 96 & & 38.2 & 107 & 33.6 & 94 & 28.2 & 79 & \\
\hline \multirow{3}{*}{\multicolumn{2}{|c|}{ Characteristics }} & & & & West & & & & & & & Snack & ing & & \\
\hline & & $T$ & & $T$ & & & & $p$ & & & & 2 & $T$ & & $p$ \\
\hline & & $\%$ & $n$ & $\%$ & $n$ & $\%$ & $n$ & & $\%$ & $n$ & $\%$ & $n$ & $\%$ & $n$ & \\
\hline Sex & Male & 29.3 & 127 & 35.7 & 155 & 35.0 & 152 & 0.040 * & 33.9 & 147 & 31.8 & 138 & 34.3 & 149 & 0.627 \\
\hline & Female & 37.3 & 167 & 31.0 & 139 & 31.7 & 142 & & 32.8 & 147 & 34.8 & 156 & 32.4 & 145 & \\
\hline Tanner status $¥$ & $1-3$ & 32.4 & 136 & 36.0 & 151 & 31.7 & 133 & 0.324 & 33.3 & 140 & 32.9 & 138 & 33.8 & 142 & 0.900 \\
\hline & $4-5$ & 33.9 & 149 & 31.2 & 137 & 34.9 & 153 & & 33.9 & 149 & 33.7 & 148 & 32.4 & 142 & \\
\hline Weight status $\ddagger$ & Underweight & 27.9 & 12 & 41.9 & 18 & 30.2 & 13 & 0.675 & 34.9 & 15 & 27.9 & 12 & 37.2 & 16 & 0.408 \\
\hline & Normal Weight & 35.4 & 136 & 30.5 & 117 & 34.1 & 131 & & 35.9 & 138 & 30.5 & 117 & 33.6 & 129 & \\
\hline & Overweight & 31.6 & 87 & 34.2 & 94 & 34.2 & 94 & & 33.1 & 91 & 34.2 & 94 & 32.7 & 90 & \\
\hline & Obesity & 32.8 & 59 & 36.1 & 65 & 31.1 & 56 & & 27.8 & 50 & 39.4 & 71 & 32.8 & 59 & \\
\hline Sleep Hours & $\geq 9 \mathrm{~h}$ & 33.9 & 80 & 32.2 & 76 & 33.9 & 80 & 0.663 & 33.5 & 79 & 31.4 & 74 & 35.2 & 83 & 0.611 \\
\hline & $<9 h$ & 32.7 & 174 & 35.5 & 189 & 31.8 & 169 & & 34.8 & 185 & 33.7 & 179 & 31.6 & 168 & \\
\hline $\begin{array}{c}\text { School } \\
\text { administrative }\end{array}$ & Public & 34.6 & 114 & 31.5 & 104 & 33.9 & 112 & 0.670 & 31.5 & 104 & 37.9 & 125 & 30.6 & 101 & 0.082 \\
\hline & Private & 32.8 & 178 & 34.4 & 187 & 32.8 & 178 & & 34.4 & 187 & 30.6 & 166 & 35.0 & 190 & \\
\hline $\begin{array}{l}\text { School feeding } \\
\text { program }\end{array}$ & Yes & 36.9 & 103 & 35.5 & 99 & 27.6 & 77 & $0.046^{*}$ & 27.6 & 77 & 32.3 & 90 & 40.1 & 112 & 0.007 * \\
\hline & No & 31.7 & 191 & 32.3 & 195 & 36.0 & 217 & & 36.0 & 217 & 33.8 & 204 & 30.2 & 182 & \\
\hline Maternal & No & 35.2 & 183 & 33.7 & 175 & 31.2 & 162 & 0.197 & 33.1 & 172 & 34.2 & 178 & 32.7 & 170 & 0.719 \\
\hline & Yes & 30.2 & 102 & 33.4 & 113 & 36.4 & 123 & & 33.7 & 114 & 31.7 & 107 & 34.6 & 117 & \\
\hline $\begin{array}{l}\text { Maternal } \\
\text { education }\end{array}$ & $\geq 12$ years & 33.0 & 191 & 35.3 & 204 & 31.7 & 183 & 0.265 & 35.1 & 203 & 32.5 & 188 & 32.4 & 187 & 0.561 \\
\hline & $<12$ years & 33.2 & 93 & 30.4 & 85 & 36.4 & 102 & & 31.4 & 88 & 34.6 & 97 & 33.9 & 95 & \\
\hline
\end{tabular}

T: Tertile adherence. All values are shown as percentages (for categorical). $¥$ Tanner status: girls were evaluated according to their breast development and boys were evaluated according their genitalia development [25]. $\ddagger$ Nutritional status, BMI-for-age $z$ score: underweight $\leq-1 \mathrm{SD}$, normal $<-1 \mathrm{SD}$ and $<+1 \mathrm{SD}$, overweight $\geq+1 \mathrm{SD}$ and $<+2 \mathrm{SD}$, obesity $\geq+2 \mathrm{SD}$ [24]. $£$ School feeding program: adolescents receive some food services of feeding program (yes or no). ${ }^{*} X^{2}$ Pearson tests, $p$ value $<0.05$.

\subsection{Nutrient Intake and Adherence to Dietary Patterns}

Associations between nutrient intake and adherence to dietary patterns are shown in Table 4. Adolescents with higher adherence to the "Breakfast/Light dinner", "Western", and "Snacking" patterns (third tertile) had a higher energy intake than those who showed lower adherence (first tertile). The contribution of saturated fats was significantly higher in the "Western" pattern, whereas added 
sugars accounted for a significantly higher percentage of energy contribution for adolescent "Snacking" consumers. The "Natural foods" and "Breakfast/Light dinner" patterns were associated with lower intakes of saturated fats but a higher intake of sodium.

Table 4. Medians nutrient intake according to tertile ${ }^{\dagger}$ of adherence to dietary patterns in GOCS adolescents ( $n: 882)$.

\begin{tabular}{|c|c|c|c|c|c|c|c|c|c|c|c|c|c|}
\hline \multirow{2}{*}{$\begin{array}{l}\text { Dietary } \\
\text { Patterns }\end{array}$} & & \multicolumn{3}{|c|}{ Saturated Fat (\%) IE $\S$} & \multicolumn{3}{|c|}{ Added Sugars (\%) IE ${ }^{\S}$} & \multicolumn{3}{|c|}{ Sodium mg/1000 kcal } & \multicolumn{3}{|c|}{ Energy/day (kcal) } \\
\hline & & Medians & $\mathrm{IQR}^{+}$ & $p \ddagger$ & Medians & $\mathrm{IQR}^{+}$ & $p \ddagger$ & Medians & $\mathrm{IQR}^{+}$ & $p \ddagger$ & Medians & $\mathrm{IQR}^{+}$ & $p \ddagger$ \\
\hline \multirow{2}{*}{$\begin{array}{l}\text { Breakfast/Light } \\
\text { dinner }\end{array}$} & tertile 1 & 9.8 & 1.8 & $0.001^{a b c}$ & 18.3 & 6.6 & 0.285 & 1468 & 286 & $0.001^{a b}$ & 1754 & 504 & $0.017^{c}$ \\
\hline & tertile 3 & 9.0 & 2.4 & & 17.3 & 6.4 & & 1515 & 254 & & 1819 & 427 & \\
\hline \multirow[t]{2}{*}{ Natural foods } & tertile 1 & 9.7 & 2.2 & $0.001 \mathrm{bc}$ & 17.5 & 6.5 & 0.949 & 1478 & 257 & $0.017^{\mathrm{ab}}$ & 1809 & 478 & $0.194^{\mathrm{c}}$ \\
\hline & tertile 2 & 9.6 & 2.2 & & 17.9 & 6.3 & & 1521 & 286 & & 1763 & 442 & \\
\hline \multirow{2}{*}{ Western } & tertile 2 & 9.4 & 2.2 & & 18.2 & 7.3 & & 1514 & 272 & & 1733 & 429 & \\
\hline & tertile 3 & 9.7 & 2.5 & & 17.2 & 6.2 & & 1526 & 247 & & 1913 & 417 & \\
\hline \multirow[t]{3}{*}{ Snacking } & tertile 1 & 9.6 & 2.1 & $0.215^{\mathrm{a}}$ & 16.5 & 6.5 & $0.001^{b c}$ & 1528 & 263 & $0.001^{b c}$ & 1704 & 470 & $0.001^{b c}$ \\
\hline & tertile 2 & 9.5 & 2.3 & & 16.8 & 6.5 & & 1553 & 288 & & 1887 & 446 & \\
\hline & tertile 3 & 9.5 & 2.6 & & 19.3 & 6.2 & & 1460 & 258 & & 1754 & 504 & \\
\hline
\end{tabular}

Tertile 1 lower adherence, tertile 3 higher adherence. $\S$ IE, energy intake day. + Interquartile range (IQR). ${ }^{\text {a Significant }}$ difference between tertile 1 and 2 of the factor scores. ${ }^{b}$ Significant difference between tertile 1 and 3 of the factor scores. ${ }^{c}$ Significant difference between tertile 2 and 3 of the factor scores. $\ddagger$ Kruskal-Wallis test and Dunn's test post hoc, $p$ value $<0.05$.

\subsection{Adherence to Dietary Patterns and Overweight}

When adjusted for covariates (i.e., sex, age, Tanner status, misreporting, maternal obesity, and education level), adolescents with higher adherence to the "Natural foods", "Western", and "Snacking" patterns had higher odds of being classified as overweight than those with lower adherence $(\mathrm{OR}=1.83,95 \% \mathrm{CI}: 1.21-2.75$; $\mathrm{OR}=1.67,95 \% \mathrm{CI}: 1.10-2.52$ and $\mathrm{OR}=1.86,95 \% \mathrm{CI}$ : $1.23-2.79$, respectively). The "Breakfast/Light dinner" pattern was not significantly associated with overweightness (Table 5).

Table 5. Crude odds ratio and adjusted odds ratio of overweight, according to tertile of dietary pattern practiced by GOCS adolescents. Chile, 2014-2015.

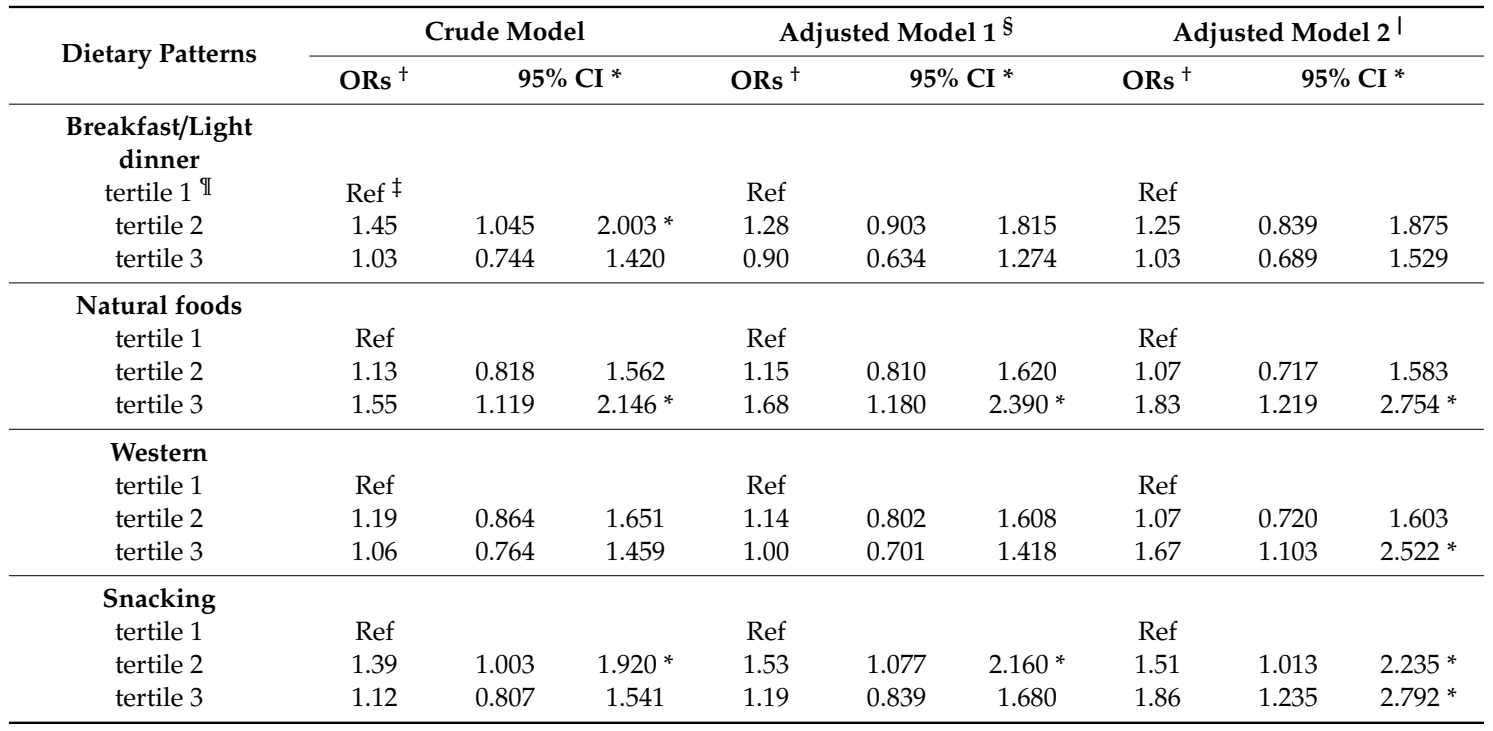

*95\% Confidence Intervals, value $p<0.05$. † ORs: odds ratio, CI: confidence interval. ‡ Ref: reference. § Logistic model 1: adjusted for sex, age, tanner, maternal obesity, maternal education ( $n: 816)$. | Logistic model 2: adjusted for sex, age, tanner, maternal obesity, maternal education and misreporting $(n: 816)$. "II Tertile 1 lower adherence, tertile 3 higher adherence. 


\subsection{Sensitivity Analyses}

We tested other combinations of food groups that had low factor loadings (e.g., we combined the eggs and cheeses groups, and confectionary, desserts, and ice cream groups, for their commonalities) but their communalities and factor loadings did not improve; indeed, the consistency of the findings remained the same (data not shown).

\section{Discussion}

The present study identified four major dietary patterns among Chilean adolescents: "Breakfast/Light dinner", "Natural foods", "Western", and "Snacking" patterns. All dietary patterns identified in this sample were associated with either a high caloric intake or overconsumption of a nutrient of public health concern, such as saturated fats and added sugars or sodium. Moreover, the "Western" and "Snacking" patterns showed a positive association with overweightness; however, the "Natural foods" pattern was also associated with overweightness; these adolescents may have been consuming these foods in an attempt to combat their health problems.

In this population, the "Breakfast/Light dinner" pattern showed the highest percentage of dietary variance. This pattern describes a very typical diet of the Chilean population [21]; it accounts for two of the four main meals in Chile, i.e., breakfast, lunch, "Light dinner" (similar to breakfast in terms of food consumed, but it is taken at 5:00-8:00 pm) and dinner. In Chile, it has been recently observed that dinner is being increasingly replaced by "Light dinner" and, currently, only one in four Chileans over 18 years of age eat dinner [21]. This may have a potential effect on the shortfall of quality nutrients, as dinner in some cultures often includes a variety of healthy meats, vegetables, integral cereals, and fruits [32]. In this study, adolescents with a higher adherence to the "Breakfast/Light dinner" pattern had higher energy and sodium intakes, and obese adolescents showed a higher adherence to this pattern. Bread, which is one of the main components of this pattern and a major source of energy and sodium intake, is the most consumed food among Chileans (i.e., $86.5 \mathrm{~kg} /$ person/year), particularly among low-income individuals [21,33,34]. The Latin American Study of Nutrition and Health also observed that refined-grain products, such as bread, are a major source energy in Latin American countries; however, Chile had a higher percentage (25.13\%) of energy contribution through refined-grains than Colombia (11.71\%) [35], which has a lower obesity prevalence in adolescents [8].

Studies have shown that dietary patterns with high factor loadings, e.g., the bread group, have higher energy densities and positive associations with overweightness [36-38]. We found that foods groups of this pattern (white bread, sugar, margarine, cold cut, and tea) provide low quality nutrition, similar to "traditional breakfast" patterns found by Oliveira et al. in Brazilian adults [39]; however, we did not find this food group to be associated with overweightness. This might require further study, as our sample was homogenous in terms of socioeconomic status (SES), and this pattern is a dietary behavior typical of the Chilean population [21]. However, our findings that this pattern explained the higher variability of diet is worrying, because adolescence is a stage critical for rapid growth, and to maintain this behavior could lead to negative health consequences in adult life [4].

The "Natural foods" pattern was the second most relevant in this population. This pattern could be considered healthier because it has a higher factor loading of natural foods, such as vegetables and meats. Furthermore, this pattern was more frequent among those not participating in the school feeding program (based on SES) and whose mothers had a higher education level. The latter is in agreement with previous reports that high SES individuals have healthier dietary behaviors than their counterparts with lower SES [21]. In addition, in line with the literature, we found an inverse association between adherence to the "Natural foods" dietary pattern and energy intake [12,37,40]. In contrast with this finding and that of other studies that show a likely protective role against obesity [15,41], we found that the "Natural foods" pattern was associated with a higher odds of being classified as overweight. Cross-sectional studies in Mexican adolescents [42] and Norwegian children also have found a positive association between higher adherence to a healthy dietary pattern and overweightness $[43,44]$. We believe this is explained by reverse causality [45], whereby overweight 
adolescents have either already changed their diet to a more healthy one before the assessment or they under-report unhealthy food and over-report healthy food [46].

The "Natural foods" pattern was mainly composed of natural foods, and we did not expect it to be associated with high sodium and low saturated fat intakes. Negative factor loadings of processed meats, cold cut, and junk food may explain the low intake of saturated fat, and the addition of salt (higher factor loadings of oil, lemon, salt, and vinegar foods) to salads, which is in line with recent analyses of the National Survey of Food Consumption [21], could also explain the high sodium intake. These results are different from those found for American children and adolescents, where the main sources sodium were pizza, Mexican dishes, sandwiches, breads, cold cuts, soups, savory snacks, etc. [47]. Assessing sodium intake using $24 \mathrm{HR}$ is a challenge for epidemiological studies, because intake is likely to be incorrectly estimated or not accurately recalled. We used household measures together with a photo atlas [21] and up-to-date labelling of food to aid in the accurate estimation of sodium intake. These results highlight the need for consumer awareness and educational activities, in conjunction with other salt-reduction strategies, to address this public health problem [48].

"Western" and "Snacking" patterns were characterized by unhealthy and processed foods of low nutritional quality, with the exception of the meats group and the rice, pastas, and potatoes group, which are good sources of protein and carbohydrates and are staple Chilean foods [21]. It is important to note that the "Western" pattern was characterized by a high negative loading of the homemade dishes group (homemade dishes or healthy meals consisting of potatoes, carrots, corn, pumpkin, and red meat or poultry stews), which could indicate that adolescents who have high scores for this pattern consume more ready-to-eat or ready-to-heat foods than vegetable soups and legume stews with proteins (animal or vegetable). Such dishes require a longer cooking time but are nutritionally balanced and culturally appropriate for adolescents, according to Chilean dietary guidelines [32,49]. These results are consistent with the evidence for the increase in expenditure on ready-to-eat meals, SSBs, and away-from-home foods in Chile in recent years [50,51]. There is evidence that consumption of SSBs promotes weight gain in children and adults; therefore, discouraging the consumption of SSBs is an important way to help children achieve and maintain a healthy body weight [52]. As expected, adolescents with higher adherence to the "Western" and "Snacking" patterns had higher energy intakes, although the nutrient sources differed between these patterns, i.e., saturated fat for the "Western" (from processed meat and cold-cuts) and added sugars (from flavored milk, cookies, and cakes) for the "Snacking" patterns. These findings are in line with dietary patterns high saturated fat and added sugar found for Australian adolescents [37]. According to a systematic review on empirical dietary patterns [41] and other studies in Brazil [36], Mexico [42], and Colombia [53], dietary patterns named "Snack" and "Western" (characterized by processed foods of low nutritional quality) were also associated with an increased risk of overweight in children and adolescents; these results are in line with our findings. This is important because the objective of front labeling and the control of food marketing aimed at children in Chile is to regulate the consumption of unhealthy food groups (including processed meat, soft drinks, cookies, and cakes) and to inform consumers, through a warning symbol on packaged products, that they are high in energy, saturated fats, total sugars, or sodium [16].

Dietary patterns were, in general, homogeneously distributed among the study sample. We observed that boys had higher adherence scores for "Western" patterns than girls, probably because girls under-report these types of foods, and because girls are more vulnerable to social aesthetic standards [54]. We also observed that participation in the school feeding program protected adolescents from the "Western" dietary pattern, probably because this program provides beneficiaries with a free breakfast and lunch that includes fresh fruits and vegetables, as well as fulfilling nutrient requirements based on dietary guidelines $[49,55]$. However, participation in the school feeding program did not protect individuals from the "Snacking" pattern, which is probably because snacks are also available inside schools, in addition to main meals [56].

The limitations of the study should be considered when interpreting its results. First, its crosssectional design limits us from establishing causality. Besides, the present study used EFA, a method 
that involves decision-making by researchers at various stages of the modeling process, such as decisions on grouping and the number of factors to be selected. For this reason, widely-used nutritional epidemiology procedures were applied and validated to counterbalance these weaknesses [57] and several sensitivity analyses confirmed the validity of our findings. Empirical dietary patterns usually differ across studies. For that reason, we tried to label the found dietary patterns with the same nomenclature than other studies [14]. However, we also considered the way the Chilean population eats the foods included in the patterns to reflect their habitual meals. Although we used 24HRs, which might be subject to recall bias and do not estimate the usual dietary intake, $61 \%$ of the sample underwent a second measurement within 6 months. This allowed us to estimate the usual intake, adjusting for intra-individual variance according to the Multiple Source Method, and to increase the reliability of the results [27]. The interviews were reported by parents or caregivers who had access to the school feeding program menus, which complemented the dietary data and followed the "Multiple-Pass Method." The study population was somewhat homogeneous in terms of SES, and the inclusion of more variety may have had an effect on the differences between groups [58]. Analyses of the adherence to dietary patterns and overweight status were not adjusted for physical activity due to a lack of information, but it was possible to adjust the final models for the Tanner pubertal stage (i.e., a relevant confounding factor among adolescents) [1]. Finally, this study considered adjusting the regression models by misreporting to account for possible measurement errors associated with self-reported dietary data $(\mathrm{R} 24 \mathrm{H})$, which could impact the obtained dietary patterns, and the association with overweight [46].

\section{Conclusions}

In a sample of low-middle income adolescents from Chile, a country with one the highest prevalence of obesity worldwide, we found that common dietary patterns are related to high consumption of calories and nutrients of public health concern were associated with overweightness, confirming the hypothesis of this study. We did not identify dietary patterns that could be considered healthy, indicating that intake of healthy foods among this age group is random and does not conform to an organized pattern. Our results are of concern and demonstrate poor dietary quality during a period that can have long-lasting implications for both the individual and their potential offspring. It is important to evaluate whether the ongoing obesity prevention policies will be able to modify these unhealthy behaviors among a traditionally resistant age-group.

Supplementary Materials: The following are available online at http://www.mdpi.com/2072-6643/12/7/2083/s1, Table S1: Description of the foods that composed each of the 29 food groups included in the factor analysis. GOCS Study, Chile 2014-2015.

Author Contributions: Conceptualization, A.M.A., R.M.F.; methodology, A.M.A. and R.M.F.; formal analysis, A.M.A.; investigation, A.M.A.; writing—original draft preparation, A.M.A.; writing—review and editing, R.M.F., X.P.M., X.C.S. and C.C.A.; supervision, R.M.F. and C.C.A.; project administration, C.C.A.; funding acquisition, C.C.A. All authors have read and agreed to the published version of the manuscript.

Funding: This work was supported by grant Fondecyt \#1120326, \#1161436, \#1191421, \#1181370, DIUV \#48/2013.

Acknowledgments: This work was supported by the CONICYT (Chilean National Commission for Scientific and Technological Research) "Becas Chile" Doctoral Fellowship program: Grant N $^{\circ} 72160434$. We would like to thank Michele Castro for help with the statistical analysis. We thank GOCS families and adolescents for their participation.

Conflicts of Interest: The authors declare no conflict of interest.

\section{References}

1. Villamor, E.; Jansen, E.C. Nutritional Determinants of the Timing of Puberty. Annu. Rev. Public Health 2016, 37, 33-46. [CrossRef] [PubMed]

2. Simmonds, M.; Llewellyn, A.; Owen, C.G.; Woolacott, N. Predicting adult obesity from childhood obesity: A systematic review and meta-analysis. Obes. Rev. 2016, 17, 95-107. [CrossRef] 
3. World Health Organization. Report of the Commission on Ending Childhood Obesity: World Health Organization; WHO: Geneva, Switzerland, 2016; Available online: https://www.who.int/end-childhoodobesity/publications/echo-report/en/ (accessed on 1 October 2019).

4. Patton, G.C.; Olsson, C.A.; Skirbekk, V.; Saffery, R.; Wlodek, M.E.; Azzopardi, P.S.; Stonawski, M.; Rasmussen, B.; Spry, E.; Francis, K.; et al. Adolescence and the next generation. Nature 2018, 554, 458-466. [CrossRef]

5. Corvalán, C.; Garmendia, M.L.; Jones-Smith, J.; Lutter, C.K.; Miranda, J.J.; Pedraza, L.S.; Popkin, B.M.; Ramirez-Zea, M.; Salvo, D.; Stein, A.D. Nutrition status of children in Latin America. Obes. Rev. 2017, 18 (Suppl. S2), 7-18. [CrossRef] [PubMed]

6. Rokholm, B.; Baker, J.L.; Sørensen, T.I. The levelling off of the obesity epidemic since the year 1999-A review of evidence and perspectives. Obes. Rev. 2010, 11, 835-846. [CrossRef] [PubMed]

7. Popkin, B.M.; Reardon, T. Obesity and the food system transformation in Latin America. Obes. Rev. 2018, 19, 1028-1064. [CrossRef] [PubMed]

8. Rivera, J.; de Cossío, T.G.; Pedraza, L.S.; Aburto, T.C.; Sánchez, T.G.; Martorell, R. Childhood and adolescent overweight and obesity in Latin America: A systematic review. Lancet Diabetes Endocrinol. 2014, 2, 321-332. [CrossRef]

9. Michels, K.B.; Schulze, M.B. Can dietary patterns help us detect diet-disease associations? Nutr. Res. Rev. 2005, 18, 241-248. [CrossRef]

10. Leal, D.B.; de Assi, M.A.A.; de Fragas Hinnig, P.; Schmitt, J.; Lobo, A.S.; Bellisle, F.; di Pietro, P.F.; Vieira, F.K.; De Moura Araujo, P.H.; de Andrade, D.F. Changes in Dietary Patterns from Childhood to Adolescence and Associated Body Adiposity Status. Nutrients 2017, 9, 1098. [CrossRef]

11. Wirfält, E.; Drake, I.; Wallström, P. What do review papers conclude about food and dietary patterns? Food Nutr. Res. 2013, 57, 20523. [CrossRef]

12. United States Department of Agriculture. A Series of Systematic Reviews on the Relationship between Dietary Patterns and Health Outcomes. Available online: https:/nesr.usda.gov/sites/default/files/2019-04/ DietaryPatternsReport-FullFinal.pdf (accessed on 13 March 2019).

13. Hu, F.B. Dietary pattern analysis: A new direction in nutritional epidemiology. Curr. Opin. Lipidol. 2002, 13, 3-9. [CrossRef] [PubMed]

14. Liberali, R.; Kupek, E.; Assis, M.A.A. Dietary Patterns and Childhood Obesity Risk: A Systematic Review. Child Obes. 2020, 16, 70-85. [CrossRef] [PubMed]

15. de Magalhães Cunha, C.; Costa, P.R.F.; de Oliveira, L.P.M.; de Oliveira, L.P.; Pitangueira, J.C.D.; Oliveira, A.M. Dietary patterns and cardiometabolic risk factors among adolescents: Systematic review and meta-analysis. Br. J. Nutr. 2018, 119, 859-879. [CrossRef] [PubMed]

16. Corvalán, C.; Reyes, M.; Garmendia, M.L.; Uauy, R. Structural responses to the obesity and non-communicable diseases epidemic: Update on the Chilean law of food labelling and advertising. Obes. Rev. 2019, 20, 367-374. [CrossRef] [PubMed]

17. Kain, J.; Corvalan, C.; Lera, L.; Galvan, M.; Uauy, R. Accelerated growth in early life and obesity in preschool Chilean children. Obesity 2009, 17, 1603-1608. [CrossRef]

18. Corvalan, C.; Uauy, R.; Kain, J.; Martorell, R. Obesity indicators and cardiometabolic status in 4-y-old children. Am. J. Clin. Nutr. 2010, 91, 166-174. [CrossRef]

19. Corvalán, C.; Uauy, R.; Mericq, V. Obesity is positively associated with dehydroepiandrosterone sulfate concentrations at $7 \mathrm{y}$ in Chilean children of normal birth weight. Am. J. Clin. Nutr. 2013, 97, 318-325. [CrossRef]

20. Moshfegh, A.J.; Rhodes, D.G.; Baer, D.J.; Murayi, T.; Clemens, J.C.; Rumpler, W.V.; Paul, D.R.; Sebastian, R.S.; Kuczynski, K.J.; Ingwersen, L.A.; et al. The US Department of Agriculture Automated Multiple-Pass Method reduces bias in the collection of energy intakes. Am. J. Clin. Nutr. 2008, 88, 324-332. [CrossRef]

21. Ministerio de Salud, Gobierno de Chile. Encuesta de Consumo Alimentario en Chile (ENCA). 2010. Available online: http://web.minsal.cl/enca (accessed on 10 October 2018).

22. Jury, G.; Urteaga, C. Porciones de Intercambio y Composición Química de los Alimentos de la Pirámide Alimentaria Chilena; Universidad de Chile, INTA, Centro de Nutrición Humana Facultad de Medicina: Santiago, Chile, 1999.

23. Willet, W. Nutritional Epidemiology, 3rd ed.; Oxford University Press: New York, NY, USA, 2012.

24. Onis, M.; Onyango, A.W.; Borghi, E. Development of a WHO growth reference for school-aged children and adolescents. Bull. World Health Organ. 2007, 85. [CrossRef] 
25. Tanner, J.M. Growth at Adolescence, 2nd ed.; Thomas: Springfield, IL, USA, 1962.

26. World Health Organization. Obesity: Preventing and Managing the Global Epidemic: World Health Organization. 2000. Available online: https://www.who.int/nutrition/publications/obesity/WHO_TRS_894/ en/ (accessed on 1 October 2019).

27. Haubrock, J.; Nöthlings, U.; Volatier, J.-L.; Dekkers, A.; Ocké, M.; Harttig, U.; Illner, A.-K.; Knüppel, S.; Andersen, L.F.; Boeing, H.; et al. Estimating usual food intake distributions by using the multiple source method in the EPIC-Potsdam Calibration Study. J. Nutr. 2011, 141, 914-920. [CrossRef]

28. Castro, M.A.; Baltar, V.T.; Marchioni, D.M.; Fisberg, R.M. Examining associations between dietary patterns and metabolic CVD risk factors: A novel use of structural equation modelling. Br. J. Nutr. 2016, 115, 1586-1597. [CrossRef]

29. DiStefano, C.; Zhu, M.; Mindrila, D. Understanding and using factor scores: Considerations for the applied researcher. Pract. Assess. Res. Eval. 2009, 14, 1-11.

30. Millen, B.E.; Abrams, S.; Adams-Campbell, L.; Anderson, C.A.M.; Brenna, J.T.; Campbell, W.W.; Clinton, S.; Hu, F.; Nelson, M.; Neuhouser, M.L.; et al. The 2015 Dietary Guidelines Advisory Committee Scientific Report: Development and Major Conclusions. Adv. Nutr. 2016, 7, 438-444. [CrossRef] [PubMed]

31. Kelly, M.T.; Rennie, K.L.; Wallace, J.M.; Robson, P.J.; Welch, R.W.; Hannon-Fletcher, M.P.; Livingstone, M.B.E. Associations between the portion sizes of food groups consumed and measures of adiposity in the British National Diet and Nutrition Survey. Br. J. Nutr. 2009, 101, 1413-1420. [CrossRef] [PubMed]

32. Sichieri, R.; Chiuve, S.E.; Pereira, R.A.; Lopes, A.C.; Willett, W.C. Dietary recommendations: Comparing dietary guidelines from Brazil and the United States. Cad. Saude Publica 2010, 26, 2050-2058. [CrossRef] [PubMed]

33. Quilez, J.; Salas-Salvado, J. Salt in bread in Europe: Potential benefits of reduction. Nutr. Rev. 2012, 70, 666-678. [CrossRef]

34. Cediel, G.; Reyes, M.; da Costa Louzada, M.L.; Steele, E.M.; Monteiro, C.A.; Corvalán, C.; Uauy, R. Ultra-processed foods and added sugars in the Chilean diet (2010). Public Health Nutr. 2018, 21, 125-133. [CrossRef] [PubMed]

35. Kovalskys, I.; Fisberg, M.; Gómez, G.; Pareja, R.G.; García, M.C.Y.; Sanabria, L.Y.C.; Herrera-Cuenca, M.; Rigotti, A.; Guajardo, V.; Zimberg, I.Z.; et al. Energy intake and food sources of eight Latin American countries: Results from the Latin American Study of Nutrition and Health (ELANS). Public Health Nutr. 2018, 21, 2535-2547. [CrossRef]

36. Borges, C.A.; Marchioni, D.M.L.; Levy, R.B.; Slater, B. Dietary patterns associated with overweight among Brazilian adolescents. Appetite 2018, 123, 402-409. [CrossRef]

37. Ambrosini, G.L.; Johns, D.J.; Northstone, K.; Emmett, P.M.; Jebb, S.A. Free Sugars and Total Fat Are Important Characteristics of a Dietary Pattern Associated with Adiposity across Childhood and Adolescence. J. Nutr. 2016. [CrossRef]

38. Zhen, S.; Ma, Y.; Zhao, Z.; Yang, X.; Wen, D. Dietary pattern is associated with obesity in Chinese children and adolescents: Data from China Health and Nutrition Survey (CHNS). Nutr. J. 2018, 17, 68. [CrossRef] [PubMed]

39. de Oliveira Santos, R.; Fisberg, R.M.; Marchioni, D.M.; Troncoso Baltar, V. Dietary patterns for meals of Brazilian adults. Br. J. Nutr. 2015, 114, 822-828. [CrossRef] [PubMed]

40. dos Santos Vieira, D.A.; Castro, M.A.; Fisberg, M.; Fisberg, R.M. Nutritional quality of dietary patterns of children: Are there differences inside and outside school? J. de Pediatr. 2017, 93, 47-57. [CrossRef] [PubMed]

41. Ambrosini, G.L. Childhood dietary patterns and later obesity: A review of the evidence. Proc. Nutr. Soc. 2014, 73, 137-146. [CrossRef] [PubMed]

42. Gutiérrez-Pliego, L.E.; del Socorro Camarillo-Romero, E.; Montenegro-Morales, L.P.; de Jesus Garduño-García, J. Dietary patterns associated with body mass index (BMI) and lifestyle in Mexican adolescents. BMC Public Health 2016, 16, 850. [CrossRef] [PubMed]

43. Oellingrath, I.M.; Svendsen, M.V.; Brantsæter, A.L. Eating patterns and overweight in 9- to 10-year-old children in Telemark County, Norway: A cross-sectional study. Eur. J. Clin. Nutr. 2010, 64, 1272-1279. [CrossRef]

44. Oellingrath, I.M.; Svendsen, M.V.; Brantsæter, A.L. Tracking of eating patterns and overweight-A follow-up study of Norwegian schoolchildren from middle childhood to early adolescence. Nutr. J. 2011, 10, 106. [CrossRef] 
45. Sahoo, K.; Sahoo, B.; Choudhury, A.K.; Sofi, N.Y.; Kumar, R.; Bhadoria, A.S. Childhood obesity: Causes and consequences. J. Fam. Med. Prim. Care 2015, 4, 187-192. [CrossRef]

46. Livingstone, M.B.; Robson, P.J.; Wallace, J.M. Issues in dietary intake assessment of children and adolescents. Br. J. Nutr. 2004, 92 (Suppl. S2), S213-S222. [CrossRef] [PubMed]

47. Quader, Z.S.; Gillespie, C.; Sliwa, S.A.; Ahuja, J.K.C.; Burdg, J.P.; Moshfegh, A.; Pehrsson, P.R.; Gunn, J.P.; Mugavero, K.; Cogswell, M.E. Sodium Intake among US School-Aged Children: National Health and Nutrition Examination Survey, 2011-2012. J. Acad. Nutr. Diet. 2017, 117, 39-47.e5. [CrossRef] [PubMed]

48. Trieu, K.; Neal, B.; Hawkes, C.; Dunford, E.; Campbell, N.; Rodriguez-Fernandez, R.; Legetic, B.; McLaren, L.; Barberio, A.; Webster, J. Salt Reduction Initiatives around the World-A Systematic Review of Progress towards the Global Target. PLoS ONE 2015, 10, e0130247. [CrossRef]

49. Ministerio de Salud, Gobierno de Chile. Aprueba Norma General Técnica N 148 sobre Guías Alimentarias para la Población; Resolución Exenta N² 260; MINSAL: Santiago, Chile, 2013.

50. Crovetto, M.; Uauy, R. Changes in processed food expenditure in the population of Metropolitan Santiago in the last twenty years. Rev. Med. Chile 2012, 140, 305-312. [CrossRef]

51. Popkin, B.M.; Hawkes, C. Sweetening of the global diet, particularly beverages: Patterns, trends, and policy responses. Lancet Diabetes Endocrinol. 2016, 4, 174-186. [CrossRef]

52. Malik, V.S.; Pan, A.; Willett, W.C.; Hu, F.B. Sugar-sweetened beverages and weight gain in children and adults: A systematic review and meta-analysis. Am. J. Clin. Nutr. 2013, 98, 1084-1102. [CrossRef] [PubMed]

53. Shroff, M.R.; Perng, W.; Baylin, A.; Mora-Plazas, M.; Marin, C.; Villamor, E. Adherence to a snacking dietary pattern and soda intake are related to the development of adiposity: A prospective study in school-age children. Public Health Nutr. 2014, 17, 1507-1513. [CrossRef] [PubMed]

54. Forrestal, S.G. Energy intake misreporting among children and adolescents: A literature review. Matern Child Nutr. 2011, 7, 112-127. [CrossRef] [PubMed]

55. Ministerio de Educacion, Junta Nacional de Auxilio Escolar y Becas. Programa de Alimentacion Escolar Chile. Available online: https://www.junaeb.cl/programa-de-alimentacion-escolar (accessed on 10 July 2018).

56. Bustos, N.; Kain, J.; Leyton, B.; Olivares, S. Colaciones habitualmente consumidas por niños de escuelas municipalizadas: Motivaciones para su elección. Rev. Chil. de Nutr. 2010, 37, 178-183. [CrossRef]

57. Gleason, P.M.; Boushey, C.J.; Harris, J.E.; Zoellner, J. Publishing nutrition research: A review of multivariate techniques_Part 3: Data reduction methods. J. Acad. Nutr. Diet. 2015, 115, 1072-1082. [CrossRef]

58. De Fragas Hinnig, P.; Monteiro, J.S.; de Assis, M.A.A.; Levy, R.B.; Peres, M.A.; Perazi, F.M.; Porporatti, A.L.; De Luca Canto, G. Dietary Patterns of Children and Adolescents from High, Medium and Low Human Development Countries and Associated Socioeconomic Factors: A Systematic Review. Nutrients 2018, 10, 436. [CrossRef]

(C) 2020 by the authors. Licensee MDPI, Basel, Switzerland. This article is an open access article distributed under the terms and conditions of the Creative Commons Attribution (CC BY) license (http://creativecommons.org/licenses/by/4.0/). 